\title{
LA MEMORIA DOCUMENTAL DEL EXILIO REPUBLICANO ESPAÑOL EN LOS ARCHIVOS ESTATALES A TRAVÉS DEL PORTAL DE ARCHIVOS PARES
}

\section{The documentary memory of the Spanish republican exile in the national archives through archives portal pares}

\section{$M^{\text {a }}$ Josefa Villanueva Toledo}

Centro de Información Documental de Archivos (CIDA) Subdirección General de los Archivos Estatales josefa.villanueva@cultura.gob.es

Cómo citar este artículo/Citation:

$\mathrm{M}^{\mathrm{a}}$ Josefa Villanueva Toledo, "La memoria documental del exilio republicano español en los archivos estatales a través del portal de archivos pares", Hispania Nova, 1 Extraordinario (2021): 47 a 80 .

DOI: https://doi.org/10.20318/hn.2021.6179

\begin{abstract}
Copyright: (C) HISPANIA NOVA es una revista debidamente registrada, con ISSN 1138-7319 y Depósito Legal M 9472-1998. Los textos publicados están -si no se indica lo contrario- bajo una licencia Reconocimiento-Sin obras derivadas 3.0 España de Creative Commons. Puede copiarlos, distribuirlos y comunicarlos públicamente siempre que cite su autor y la revista y la institución que los publica y no haga con ellos obras derivadas. La licencia completa se puede consultar en: http://creativecommons.org/licenses/by-nd/3.0/es/deed.es
\end{abstract}

\begin{abstract}
Resumen: El objeto del artículo es analizar el estado de la cuestión de los fondos documentales que custodian los Archivos Estatales del Ministerio de Cultura sobre el Exilio republicano español de 1939 y su retorno a España, así como la descripción y digitalización de los mismos. Tiene como finalidad poner estos recursos archivísticos a disposición del usuario especializado y del público en general a través del Portal de Archivos Españoles, PARES.
\end{abstract}

Palabras clave: Archivos Estatales españoles, Exilio republicano español, fuentes documentales, bases datos, Portal PARES 
Abstract: The purpose of this article is to analyse the state of documentary fonds in Spanish National Archives about Republican Exile and its return to Spain, as well as their description and digitization. Its aim is making these archival resources available to both specialized users and general public through the Spanish Archives Portal, PARES

Keywords: Spanish National Archives, documentary resources, Spanish Republican Exile, documentary sources, databases, PARES Portal

\section{INTRODUCCIÓN}

La Subdirección General de los Archivos Estatales se crea en 1977 en el seno del nuevo departamento ministerial de Cultura, adscribiéndose orgánicamente a la Dirección General del Patrimonio Artístico, Archivos y Museos ${ }^{1}$.

La Guerra Civil, el final abrupto de la legalidad de la II República, el inicio de la dictadura de Franco y la diáspora del Exilio posibilitaron la pérdida y dispersión de archivos y fondos documentales existiendo por ello, una laguna documental en nuestra memoria democrática contemporánea. No se debe olvidar que esta documentación forma parte de la historia de España, aunque se conserve fuera de los archivos españoles.

En este contexto, la Subdirección General de los Archivos Estatales, tendrá como acción prioritaria, desde el inicio la localización de esta documentación dispersa, que va a permitir completar las fuentes documentales de la historia española de la segunda mitad del siglo XX.

Este artículo es un texto informativo que compila los principales fondos documentales sobre el Exilio republicano español que se custodian en los Archivos Estales dependientes del Ministerio de Cultura. La mayoría de estos fondos están descritos en el Portal de Archivos Españoles, PARES, están accesibles al público en Internet y en algunos casos, la descripción del documento va acompañada de su digitalización ${ }^{2}$.

\footnotetext{
${ }^{1}$ Real Decreto 2258/1977 de 27 de agosto por el que se establece la estructura y funciones del Ministerio de Cultura (BOE 1 de septiembre).

2 PARES: http://pares.culturaydeporte.gob.es/inicio.html. La información contenida en este artículo cuenta con el visto bueno del responsable de PARES, Severiano Hernández Vicente, actual Subdirector General de los Archivos Estatales.
} 


\section{LOS PROYECTOS DE RECUPERACIÓN DE LA DIÁSPORA DOCUMENTAL EN LOS ARCHIVOS ESTATALES}

Desde los años 80 del siglo XX numerosos proyectos de la Subdirección General de los Archivos Estatales han ido encaminados a describir las fuentes documentales dispersas del Exilio. Para ello se han firmado una serie de convenios con instituciones nacionales y extranjeras, que han permitido desarrollar acuerdos bilaterales de cooperación archivística.

El desarrollo de estos proyectos ha posibilitado cumplir dos objetivos esenciales, por un lado, identificar y localizar la documentación original en aquellos países donde se conserva, y por otro, reproducirla en otro formato, inicialmente microfilm, describirla en bases de datos y ponerla a disposición del público en Internet.

La mayor parte de la documentación recuperada se ha depositado en el Centro Documental de la Memoria Histórica (CDMH) de Salamanca, y en menor medida, en el Archivo Histórico Nacional (AHN) de Madrid y en el Archivo General de la Administración (AGA) de Alcalá de Henares.

A continuación se detallan los proyectos de recuperación más destacados, como los de Historia Oral en México y Argentina, la Guía de Fuentes Documentales de la Guerra Civil y el Exilio, el Archivo de los Hermanos Mayo, el Registro de Inmigrantes Extranjeros en México, el Portal de Víctimas de la Guerra Civil y la Guía del Exilio español de 1939.

\section{Historia Oral sobre exiliados españoles en México y Argentina}

Estos proyectos de historia oral consistieron en la realización de entrevistas a españoles refugiados en México y Argentina tras el final de la Guerra Civil. Para llevarlos a cabo se firmaron convenios de colaboración con el Instituto Nacional de Antropología e Historia (INAH) de México y con la Fundación Sánchez Albornoz.

En el caso de México, la colección consta de 116 entrevistas y está formada por las grabaciones sonoras (en cintas) y sus correspondientes transcripciones literales en papel, con fechas extremas de 1978 a 1990. Como ejemplos de entrevistados destacan a personalidades tales como Francisco Ayala, Ernestina de Champourcin, Estrella 
Cortichs, Ramón Gaya, Concha Méndez o Silvia Mistral. Además, cabe señalar que los entrevistadores solían ser hijos de exiliados como Matilde Mantecón, Elena Aub o Marisol Alonso.

En lo referente a Argentina, los testimonios orales comprenden 63 entrevistas a personalidades españolas exiliadas (grabaciones más transcripciones), realizadas entre los años 1990 y 1996, destacando figuras como Rafael Alberti, Teresa León, Manuel Lamana, Álvaro Osorio Florit o la viuda de Luis Jiménez de Asúa.

El hilo conductor del diálogo es el denominado "Historia de Vida", en el que el entrevistado evoca sus recuerdos y vivencias antes, durante y después de la Guerra Civil española.

Como testimonio de supervivientes de la diáspora española, las entrevistas reflejan la realidad vivida por los transterrados y por tanto, su valor documental es inmenso. Estas colecciones se custodian en el CDMH de Salamanca y se autoriza su consulta con fines de investigación ${ }^{3}$.

\section{Guía de Fuentes para la Historia de la Guerra Civil y el Exilio}

En torno al cincuenta aniversario del inicio de la Guerra Civil Española, se reactivan estos proyectos y así se pone en marcha en 1985 la Guía de Fuentes Documentales para la Guerra Civil y el Exilio, GUCI.

Para materializar este proyecto se firman convenios con archivos iberoamericanos y con fundaciones y partidos políticos, que han permitido describir y microfilmar esa parte de la historia de España cuyo vestigio estaba fuera de los archivos estatales españoles.

GUCI ha sido una base de datos pionera pues fue la primera iniciativa pública, con información archivística a nivel de documento y a disposición del público, primero

\footnotetext{
${ }^{3}$ Proyecto de México: http://pares.mcu.es/ParesBusquedas20/catalogo/description/117004 y Proyecto de La Argentina: http://pares.mcu.es/ParesBusquedas20/catalogo/description/7224588

Las transcripciones en papel de las entrevistas de México también están accesibles en el Catálogo Colectivo de Bibliotecas, CCBAE: http://www.mcu.es/ccbae/es/consulta/registro.cmd?id=163959
} 
en los Puntos de Interés Cultural (PIC) del Ministerio de Cultura y más tarde, accesible en Internet ${ }^{4}$.

Contiene alrededor de cincuenta mil registros descriptivos sobre la materia y entre sus fondos descritos cabe destacar especialmente:

\section{Los Archivos del Exilio Filosófico Español en México}

Este proyecto supuso la microfilmación y descripción de los archivos de cuatro filósofos españoles exiliados en México tras la Guerra Civil: José Gaos, Wenceslao Roces, José M. Gallegos Rocafull y Eduardo Nicol. La reproducción en microfilm de los originales está depositada en el CDMH de Salamanca ocupando un volumen cercando al centenar de rollos.

\section{La correspondencia del escritor Max Aub}

Se trata de la descripción de la correspondencia cruzada entre el escritor exiliado en México Max Aub y cerca de mil corresponsales, entre los años 1942 y 1972 y comprende cerca de 9.000 cartas (originales en el caso de las enviadas por los corresponsales y copias mecanografiadas sin firmar las enviadas por Aub).

Además, también contiene la descripción de la correspondencia generada por su viuda, Perpetua Barjau Martín, desde la muerte de Max Aub en 1972 hasta 1982. El proyecto fue fruto del acuerdo firmado con la Fundación Max Aub, con sede en Segorbe, dónde está depositado su archivo ${ }^{5}$.

\section{Archivo del Gobierno de la II República española en el Exilio}

Tras el convenio firmado con la Fundación Universitaria Española (FUE), que custodia el Archivo del Gobierno de la II República en el Exilio, se describió y microfilmó éste, depositando la copia en el CDMH de Salamanca. En concreto, los fondos documentales descritos fueron los de Gordón Ordás, Niños Vascos, Antoni María Sbert, y las sedes del Gobierno en el Exilio de México, Chile y París ${ }^{6}$.

\section{Archivo fotográfico Hermanos Mayo y Registro de Inmigrantes en México}

\footnotetext{
${ }^{4}$ Base de datos GUCI: Guía de fuentes documentales de archivos - Ministerio de Cultura y Deporte

${ }^{5}$ Archivo de la Fundación Max Aub: http://censoarchivos.mcu.es/CensoGuia/archivodetail.htm?id=47897

${ }^{6}$ Archivo de la FUE: $\underline{\text { http://censoarchivos.mcu.es/CensoGuia/archivodetail.htm?id=37222 }}$
} 
La fructífera colaboración con el Archivo General de la Nación de México ha permitido que la Subdirección General de los Archivos Estatales llevase a cabo la reproducción de dos acervos importantes para el estudio del Exilio español y cuyos originales custodia el archivo mexicano.

El primero ha sido la reproducción de cerca de cuatro mil fotografías pertenecientes al Archivo fotográfico de los Hermanos Mayo, que documentan las actividades de los refugiados españoles a su llegada a México, entre los que se encontraban los propios miembros de la agencia fotográfica ${ }^{7}$. Las copias fotográficas en papel ingresaron en el CDMH de Salamanca y posteriormente, se han reproducido en soporte digital.

El segundo acervo que ha sido reproducido es el Registro de Inmigrantes Extranjeros en México (RIEM), concretamente los registros de los españoles llegados a México. Se trata de los formularios que los emigrantes españoles cumplimentaban a su llegada al país azteca, desde mediados del siglo XIX a mediados del XX. Una parte importante de la emigración extranjera a México procede de España y representa alrededor del 30\% del total del RIEM, siendo su número en torno a 52.000 emigrantes. En cuanto a su condición, la mitad de los españoles emigrados serían republicanos refugiados. Por tanto, este Registro en una fuente primordial para conocer la identidad de los españoles llegados a México como consecuencia del Exilio de $1939^{8}$.

El material microfilmado vino a España depositándose en el AGA. Posteriormente, se ha digitalizado y se ha incluido en el Portal de Movimientos Migratorios Iberoamericanos de PARES .

\section{Portal de Víctimas de la Guerra civil y de la represión franquista}

\footnotetext{
${ }^{7}$ Bajo la denominación de Hermanos Mayo se recoge el trabajo realizado por los miembros de dos familias de fotógrafos: los hermanos Cándido, Francisco y Julio Souza Fernández y los hermanos Faustino y Pablo del Castillo Cubillo. Durante la Guerra Civil se comprometieron con la causa republicana y por ello, se exiliaron en México en $1939 . \quad$ PARES: http://pares.mcu.es/ParesBusquedas20/catalogo/description/116998

${ }^{8}$ Pla Brugat, Dolores: "Refugiados españoles en México: recuento y caracterización”, en Los refugiados españoles y la cultura mexicana: actas de las segundas jornadas, celebradas en El colegio de México en noviembre de 1996, 381-395.

${ }^{9}$ Portal Movimientos Migratorios Iberoamericanos (PMMI):

http://pares.mcu.es/MovimientosMigratorios/buscadorAvanzadoFilter.form
} 
Esta base de datos ha sido desarrollada por la Subdirección General de los Archivos Estatales para permitir el acceso del ciudadano a los documentos relativos a las víctimas de la Guerra Civil, el Exilio y la represión franquista, en virtud del mandato de la Ley de Memoria Histórica del año $2007^{10}$.

Es un recurso nominativo que contiene cerca de un millón de registros descriptivos, que proceden del vaciado de numerosos fondos y series documentales de los Archivos Estatales: Tribunales de Responsabilidades Políticas, la Causa General, Expedientes policiales de la Dirección General de Seguridad, Expedientes de depuración de maestros, Fichero de la Político Social de la Delegación Nacional de Servicios Documentales, entre otros.

\section{Guía del Exilio Español de 1939 en los Archivos Estatales}

Coincidiendo con el 80 aniversario del inicio del Exilio de 1939, se han recopilado los recursos informativos de la Subdirección General de los Archivos Estatales sobre la materia a través de la publicación de esta Guía del Exilio ${ }^{11}$.

Con una marcada finalidad didáctica se ha estructurado en 6 hilos conductores, a modo de relato del Exilio español de 1939:

El primero pone en valor el papel de los archiveros y bibliotecarios en la salvaguarda del patrimonio durante la Guerra Civil y cómo, con la derrota y el Exilio, continuarán su labor contribuyendo al desarrollo de la profesión en sus países de acogida.

A continuación, se relatan las vicisitudes de las travesías de los principales barcos de refugiados, que llevaron a los exiliados españoles a los países de acogida en Iberoamérica dónde reiniciaron sus vidas.

En el tercero, se enumeran los principales organismos de ayuda humanitaria creados por el gobierno de la II República, para organizar el éxodo masivo de los españoles una vez finalizada la guerra.

El cuarto bloque evoca la evacuación y repatriación de menores, la salida

\footnotetext{
${ }^{10}$ Portal de Víctimas: http://pares.mcu.es/victimasGCFPortal/staticContent.form?viewName=presentacion

11 Guía del Exilio: http://www.culturaydeporte.gob.es/cultura/areas/archivos/mc/centros/cida/guias-delectura/guia-exilio-espanol-1939-archivos-estatales.html
} 
temporal o definitiva en algunos casos, de los conocidos como "Niños de la Guerra".

En el quinto, se da testimonio de los campos de refugiados que Francia levantó cerca de la frontera, a principios de 1939, para internar a los españoles derrotados, que cruzaron la frontera huyendo de las represalias del bando franquista.

Finalmente, el último apartado aporta más recursos informativos para que el usuario pueda profundizar en los temas de su interés.

\section{LA DOCUMENTACIÓN DESCRITA EN PARES SOBRE EL EXILIO Y EL RETORNO A ESPAÑA}

Hemos visto cómo la preservación de la memoria documental es un deber del Estado de Derecho a través del Ministerio de Cultura, quien la ha puesto en práctica al trabajar en la recuperación de la documentación dispersa del Exilio desde su creación.

Además se constata desde el cambio de milenio un aumento de la demanda social hacia la documentación del Exilio. Realmente, ha sido la propia sociedad española la que ha venido solicitando en las últimas décadas a la Subdirección General de los Archivos Estatales la difusión en Internet de los fondos documentales sobre Guerra Civil, franquismo y Exilio que se custodian en los Archivos Estatales. Esta corriente ha corrido paralela al inicio de la legislación memorialista por pate del gobierno español.

Esta demanda del usuario se canaliza a través de la descripción y digitalización de los documentos en el Portal PARES, plataforma de difusión de los Archivos Estatales desde que se puso en marcha en el año 2007 hasta la actualidad ${ }^{12}$.

Es imposible en un artículo mencionar todo lo descrito en PARES sobre la materia por lo que se enumera la documentación más importante para su estudio conservada en el Centro Documental de la Memoria Histórica (CDMH), en el Archivo Histórico Nacional (AHN) y en el Archivo General de la Administración (AGA).

\footnotetext{
${ }^{12}$ El Real Decreto 1798/2011 que regula el Sistema de Archivos de la Administración General del Estado, define a PARES como el sistema de información archivística de la Subdirección General de los Archivos Estatales del Ministerio de Cultura.
} 


\section{Fondos y Colecciones del Exilio en el CDMH}

El CDMH se crea en el año 2007 con la finalidad de reunir los fondos relativos al periodo comprendido entre 1936 y 1978, siendo su núcleo fundamental el AGGCE, creado por Real Decreto 426/1999 con la finalidad de conservar y disponer sus fondos documentales para la investigación, la cultura y la información ${ }^{13}$. De ahí que una parte importante de los fondos y colecciones del CDMH sean de interés para el estudio del Exilio destacando especialmente archivos personales como el de Carlos Esplá, fotográficos como el Archivo Centelles, Colecciones como la García Cerdeño, la de la Cruz Roja, la del Exilio español en Chile, Archivos de la FEDIP y el GOE, Archivo digital de Juan Negrín o la colección bibliográfica de la Biblioteca del CDMH.

\section{Archivo de Carlos Esplá}

La mayor parte del archivo del político Carlos Esplá (1895-1971) desapareció por el bombardeo de su casa madrileña durante la Guerra Civil, por lo cual lo que se conserva del mismo es la documentación de su Exilio en México.

Dicha documentación está relacionada con su cargo de Secretario de la Junta de Auxilio de los Republicanos Españoles (JARE). Además, contiene abundante correspondencia con otras personalidades refugiadas en México y los listados de embarque de los barcos llegados a América (como Sinaia, Nyassa, Mexique...). Las fechas extremas del archivo son 1916-1966 ${ }^{14}$.

Este archivo se complementa con la documentación que custodia el AGA sobre la JARE. Además, una parte de los documentos se han digitalizado ${ }^{15}$.

\section{Archivo fotográfico Agustí Centelles}

Tras fotografiar ampliamente los frentes en la Guerra Civil, el reportero gráfico Agustí Centelles se exilió en Francia y estuvo interno en varios campos (Argelès-sur-

\footnotetext{
${ }^{13}$ El Real Decreto 697/2007, de creación del CDMH, establece entre sus funciones la de reunir las fuentes de interés para el estudio de la Guerra Civil, la Dictadura franquista, el Exilio, el intercambio de españoles en campos de concentración durante la Segunda Guerra Mundial y la Transición, entre otros. Pasa a integrar al antiguo Archivo General de la Guerra Civil española, AGGCE.

${ }^{14}$ Archivo Carlos Esplá en PARES: http://pares.mcu.es/ParesBusquedas20/catalogo/description/117009

${ }^{15}$ En concreto, las Actas de la JARE han sido digitalizadas y están disponibles en la Biblioteca Virtual Cervantes: http://www.cervantesvirtual.com/nd/ark:/59851/bmc0587151
} 
Mer, y, posteriormente, Bram) en los que retrató las condiciones de vida hacinada de miles de españoles refugiados. Logró salir al encontrar un empleo en Carcasona, dónde confió a una familia francesa su obra fotográfica.

Tras el comienzo de la II Guerra Mundial Centelles se integró en la Resistencia francesa que combatía al ejército alemán y al gobierno colaboracionista de Vichy. Regresó a España siendo juzgado y condenado a arresto domiciliario e inhabilitándole para ejercer como reportero gráfico, pasando a trabajar en la fotografía publicitaria.

El archivo Centelles fue adquirido a sus hijos y consta de más de diez mil fotografías y cerca de 5.600 negativos, con un ámbito cronológico amplio desde 1931 a $1985^{16}$.

\section{Colección García Cerdeño sobre el Exilio español}

José Luis García Cerdeño fue Gran Secretario de Relaciones Exteriores del Gran Oriente Español (GOE), exiliándose en México finalizada la Guerra Civil.

El Ministerio de Cultura compró la colección al propio García Cerdeño, quien había realizado una oferta al Estado español en 1998.

Este archivo sirve de testimonio de la actividad político-social de los españoles refugiados en México y comprende documentación relacionada con la Agrupación Cultural Pablo Iglesias, el Comité Ejecutivo del PSOE en México, la JARE en México, con instituciones del Gobierno de la II República en el Exilio en México, además de documentación y objetos masónicos. También incluye fotografías, así como monografías y publicaciones periódicas ${ }^{17}$.

\section{Fondos de la Cruz Roja sobre la Guerra Civil Española y el Exilio}

Tras un acuerdo con el Comité Internacional de la Cruz Roja (CICR) se han digitalizado más de ciento treinta mil documentos, correspondientes a los años 19401958 y cuyos originales se encuentran en el Museo Internacional de la Cruz Roja en

\footnotetext{
${ }^{16}$ Archivo Fotográfico Agustín Centelles en PARES:

http://pares.mcu.es/ParesBusquedas20/catalogo/description/6978682

${ }^{17}$ Colección García Cerdeño en PARES:

http://pares.mcu.es/ParesBusquedas20/catalogo/description/117013
}

HISPANIA NOVA, $\mathrm{n}^{\circ} 1$ Extraordinario (2021), págs. 47-80

DOI: https://doi.org/10.20318/hn.2021.6179 
Ginebra. Contiene información exhaustiva sobre los exiliados y campos de concentración: informes sobre los campos, fichas de prisioneros, informes de niños desaparecidos, expedición de los Niños de Morelia, fotografías, informes de las misiones y visitas de inspección, etc. Se trata de una fuente primordial para conocer la situación de los refugiados españoles en los campos del Sur de Francia tras la salida de España $^{18}$.

\section{Colección de documentos de exiliados españoles en Chile}

Colección documental donada por exiliados españoles y sus descendientes en Chile y que contiene documentos de identidad personal, cartas, biografías, currículos, memorias, fotografías y recortes de prensa, etc. de los años 1939 a 2007.

Hay referencias a figuras exiliadas como Darío Carmona, secretario de Pablo Neruda, o a Rodrigo Soriano o fotografías del famoso barco Winnipeg, la expedición marítima más numerosa, que llevó a Chile a más de dos mil refugiados españoles, en el verano de $1939^{19}$.

\section{El archivo digital de Juan Negrín}

El archivo del científico y político Juan Negrín (1892-1956), último Jefe de Gobierno de la II República española ${ }^{20}$, se encuentra depositado en su Fundación de Las Palmas de Gran Canaria, su ciudad natal, en virtud de convenio con el Ministerio de Cultura, siendo el archivo de titularidad estatal. En el CDMH se conserva la copia digital del mismo, que comprende ciento cincuenta mil objetos digitales ${ }^{21}$.

\footnotetext{
${ }^{18}$ Fondos documentales del Comité Internacional de la Cruz Roja en PARES: http://pares.mcu.es/ParesBusquedas20/catalogo/description/7281821

${ }^{19}$ Colección de documentos de exiliados españoles en Chile en PARES: http://pares.mcu.es/ParesBusquedas20/catalogo/description/5280843

${ }^{20}$ Registro de autoridad de Juan Negrín en PARES:

http://pares.mcu.es/ParesBusquedas20/catalogo/autoridad/50735

${ }^{21}$ Archivo Juan Negrín en PARES: http://pares.mcu.es/ParesBusquedas20/catalogo/description/12685903 y Archivo de la Fundación Juan Negrín en Censo-Guía de Archivos:

http://censoarchivos.mcu.es/CensoGuia/archivodetail.htm?id=1714225
} 
La documentación del archivo se refiere fundamentalmente a la etapa de Negrín en el Exilio, en la que fundó el $\mathrm{SERE}^{22}$, para dar respuesta humanitaria a miles de españoles refugiados en Francia y en la que presidió el Gobierno de la II República en el Exilio entre 1939 y 1945.

\section{Archivo de la FEDIP}

El archivo original de la Federación Española de Internados y Deportados Políticos (FEDIP) fue donado al Ministerio de Cultura y depositado en el CDMH de Salamanca.

El archivo contiene fichas de deportados, actas y correspondencia de la Federación, listas de desaparecidos, planchas del Boletín Hispania, órgano de comunicación de la Federación, cuadros de artistas deportados o maquetas de campos de concentración nazi. Las fechas de la documentación van de 1945 a $2006^{23}$.

\section{Archivo del Gran Oriente Español en el Exilio}

El Archivo abarca el periodo comprendido entre 1939, año del traslado de sede del Gran Oriente Español (GOE) fuera de España, primero en París y luego en México y 1979, año de su retorno a España tras su legalización con la democracia ${ }^{24}$.

Contiene correspondencia oficial con otras organizaciones masónicas, destacando las cartas de Lucio Martínez Gil, Gran Maestre entre 1938 y 1955, así como normativa (bandos, edictos, etc.) y prensa masónica de México y de otros países.

También hay documentación sobre masones españoles refugiados en campos de concentración franceses, sobre actividades clandestinas de masones en la España franquista y fotografías ${ }^{25}$.

\section{Biblioteca especializada del CDMH}

\footnotetext{
${ }^{22}$ Registro de autoridad del SERE (Servicio de Evacuación de Refugiados Españoles) en PARES: http://pares.mcu.es/ParesBusquedas20/catalogo/autoridad/122873

${ }^{23}$ El Archivo de la FEDIP en PARES: http://pares.mcu.es/ParesBusquedas20/catalogo/description/117020

${ }^{24}$ Registro de autoridad del GOE en PARES:

http://pares.mcu.es/ParesBusquedas20/catalogo/autoridad/132007

${ }^{25}$ Archivo del Gran Oriente Español en el Exilio en PARES:

http://pares.mcu.es/ParesBusquedas20/catalogo/description/12729495
} 
Se trata de una importante biblioteca especializada en Guerra Civil, franquismo, Exilio y Transición. Se compone de cerca de setenta mil monografías y de unos cuatro mil títulos de publicaciones periódicas.

Para el estudio del Exilio son destacables tres colecciones bibliográficas. En primer lugar, la de Prensa de Guerra, editada durante la contienda, con más de mil títulos de prensa militar y también sindical, general, etc. En segundo lugar, la Biblioteca del Exilio de la hispanista canadiense Maryse Bertrand de Muñoz. Finalmente, el corpus bibliográfico sobre literatura concentracionaria: testimonios y memorias de autores españoles, refugiados en los campos de Francia y Norte de África, como Cimorra, Max Aub, Andújar, Federica Montseny, Valldeperes, Bartoli, Bartra, Silvia Mistral ${ }^{26}$.

Aparte de los fondos mencionados, el CDMH custodia decenas de colecciones relativas al Exilio republicano español y su retorno a España, también disponibles en el Portal PARES ${ }^{27}$.

\section{Archivos personales de exiliados en el AHN}

Los principales fondos que custodia el AHN sobre la materia son archivos personales de destacadas figuras españolas, que testimonian tanto el Exilio cultural como el político: Margarita Nelken, Eduardo Zamacois, Marcelino Pascua, Luis Araquistaín, José Giral y Diego Martínez Barrio ${ }^{28}$.

\section{Archivo de Margarita Nelken}

El archivo de la escritora y política española Margarita Nelken (1894-1968) pertenece, sobre todo, al período de su exilio vivido en México durante tres décadas, adonde llegó con su familia, invitada por el presidente Lázaro Cárdenas. Allí retomó su

\footnotetext{
${ }^{26}$ Toda la biblioteca del CDMH está catalogada en línea en el Catálogo Colectivo de Bibliotecas, CCBAE: http://www.mcu.es/ccbae/es/estaticos/contenido.cmd?pagina=estaticos/presentacion

${ }^{27}$ Otras colecciones sobre el Exilio Republicano Español en el CDMH: Asociación Descendientes del Exilio Español (ADEE); Asociación para el Estudio de los Exilios y Migraciones Ibéricos Contemporáneos (AEMIC); Proyecto de Historia Oral El Exilio en Bélgica; Colección de documentos de la embajada de México en Portugal (1935-1948); Colección de documentos del Archivo Estatal Ruso de Literatura y Arte (1827-1980); Colección de fotografías España Peregrina y Niños de la Guerra; Colección Fotográfica Fernández Zúñiga, Liga de Mutilados, Inválidos, y Viudas de la Guerra de España en Francia; Colección sobre refugiados españoles en Rep. Dominicana, entre otros. PARES: http://pares.mcu.es/ParesBusquedas20/catalogo/contiene/2855369
}

${ }^{28}$ El AHN también conserva los archivos de otras destacadas personalidades del Exilio, como Manuel Azaña, Vicente Rojo o Juan Ramón Jiménez, pero no contienen apenas documentación de ese período. 
trabajo intelectual relegado durante la II República y continuó su actividad política, que ha quedado reflejada en las cartas conservadas en su Archivo.

La documentación comprende seis agrupaciones documentales: correspondencia, documentación personal, documentación literaria, documentación política, recortes de prensa y documentación varia, con fechas extremas de 1931 a 1968 y un total de 30 legajos ${ }^{29}$.

\section{Archivo de Marcelino Pascua}

Marcelino Pascua (1897-1977) fue médico, político y embajador español y su archivo personal contiene fundamentalmente el testimonio documental de su actuación durante la Guerra Civil y el Exilio, aunque las fechas extremas son más amplias, de 1920 a 1970. En relación a la Guerra Civil, destaca la documentación de su etapa como embajador de la II República en París y Moscú, su correspondencia con otros políticos coetáneos, su implicación en acontecimientos como el depósito del oro para la compra de armamento, así como otros documentos relacionados con su pensamiento político. De su etapa en el Exilio, destaca la correspondencia, los recortes de prensa y los informes políticos ${ }^{30}$.

\section{Archivo de Luis Araquistain}

Luis Araquistain Quevedo (1886-1959) fue un periodista y político socialista que jugó un papel muy importante en la Constitución de 1931. Además, fue responsable de la Embajada española en Berlín (1932-1933) y en París (1936-1937), falleciendo en el Exilio en Ginebra en 1959.

Su archivo, con fechas extremas de 1933 a 1959, consta de correspondencia, obra literaria y periodística, documentación política y privada. Es interesante la correspondencia y su producción literaria y periodística.

Cabe destacar la documentación política de su época de embajador, los diarios de sesiones de las Cortes Republicanas y alocuciones de radio, informes, telegramas,

\footnotetext{
${ }^{29}$ Archivo de Margarita Nelken en PARES:

http://pares.mcu.es/ParesBusquedas20/catalogo/description/172335

${ }^{30}$ Archivo de Marcelino Pascua en PARES:

http://pares.mcu.es/ParesBusquedas20/catalogo/description/172336
}

HISPANIA NOVA, $n^{\circ} 1$ Extraordinario (2021), págs. 47-80

DOI: https://doi.org/10.20318/hn.2021.6179 
etc. de la Guerra Civil. Contiene además información sobre partidos políticos y sindicatos en el Exilio y documentos relacionados con la propiedad del Guernica, así como todo un dossier sobre dicho cuadro desde 1937 hasta su llegada a España ${ }^{31}$.

\section{Archivo de Eduardo Zamacois}

El novelista Eduardo Zamacois (1876-1971) nació en Cuba, de padres españoles y murió en La Argentina. Fue cronista en el frente de Madrid hasta 1937, trasladándose luego a Valencia y Barcelona. En 1938 edita su novela "El asedio de Madrid". Se exilió en Francia y de ahí pasó a México, Estados Unidos y, finalmente, se instaló en La Argentina.

El archivo fue adquirido por compra y las fechas extremas son 1923-1972. Se compone de la correspondencia del autor, así como de algunos de sus manuscritos. En la correspondencia se diferencian las cartas de la Guerra Civil y las de la época del Exilio, a través de las cuales se puede establecer su periplo vital, los personajes con los que tuvo relación, los trabajos que tuvo que realizar o los avatares de su vida privada. Junto a esta correspondencia se localizan algunos documentos personales, fotografías y recortes de prensa $^{32}$.

\section{Archivo José Giral}

Tras firmar un convenio con la familia, el archivo de José Giral Pereira (18791962), hombre de ciencia y político, fue depositado en el AHN de Madrid. Fue catedrático de Química y en 1931 fue nombrado rector de la Universidad Central de Madrid. Fundó el partido Acción Republicana con Manuel Azaña. Al inicio de la Guerra Civil aceptó el cargo de Presidente del Gobierno hasta septiembre de 1936 y luego, siguió encargándose de distintos ministerios durante la contienda. Marchó al Exilio con su familia y en 1945, tras la muerte de Azaña y la renuncia de Diego Martínez Barrio, asumió la presidencia de la II República en el Exilio.

\footnotetext{
${ }^{31}$ Archivo de Luis Araquistain en PARES:

http://pares.mcu.es/ParesBusquedas20/catalogo/description/172362

${ }^{32}$ Archivo de Eduardo Zamacois Quintana en PARES:

http://pares.mcu.es/ParesBusquedas20/catalogo/description/3697344
}

HISPANIA NOVA, $n^{\circ} 1$ Extraordinario (2021), págs. 47-80

DOI: https://doi.org/10.20318/hn.2021.6179 
El archivo se compone de más de siete mil cartas y documentos, cuyas fechas extremas son de 1888 hasta 1998, perteneciendo la mayor parte al período de la Guerra Civil y el Exilio, entre los años 1936 a 1955. Sobresale la correspondencia de carácter político de su etapa como Presidente de la II República en el Exilio. Además, destacan las fotografías de carácter familiar y oficial como fotografías de barcos con refugiados españoles, la reunión de profesores de la $\operatorname{UPUE}^{33}$ en La Habana de 1946, mítines en el teatro Abreu de México, la Delegación de la Unesco en París o las fotografías de los Colegios Madrid y Luis Vives en México ${ }^{34}$.

\section{Archivo Diego Martínez Barrio}

El político español Diego Martínez Barrio (1883-1962) fue Presidente del Consejo de Ministros en 1933 y 1936, presidente de las Cortes en 1936 y Presidente de la II República en el Exilio.

El archivo está formado por 26 legajos que contiene básicamente la documentación relativa a su gestión como Presidente de la República en el Exilio, siendo la correspondencia con los diferentes políticos del momento la documentación más abundante y destacada. También hay legislación, actos conmemorativos, entrevistas con políticos internacionales, discursos, sus memorias y diarios, y los documentos que testimonian el sostenimiento económico del Gobierno de la II República en el Exilio ${ }^{35}$.

Además de estos archivos personales, el AHN custodia documentación sobre la materia en la denominada "Sección de Fondos Contemporáneos", que recoge documentación producida por la Administración Central en los siglos XIX-XX. También ingresó por donación el archivo de José Martínez Guerricabeitia, refugiado en Francia y fundador de la editorial Ruedo Ibérico, principal editorial antifranquista del Exilio español ${ }^{36}$.

\footnotetext{
${ }^{33}$ UPUE: Unión de Profesores Universitarios Españoles en el Extranjero.

${ }^{34}$ Archivo de José Giral Pereira en PARES:

http://pares.mcu.es/ParesBusquedas20/catalogo/description/5569515

${ }^{35}$ Archivo de Diego Martínez Barrio en PARES:

http://pares.mcu.es/ParesBusquedas20/catalogo/description/172332

${ }^{36}$ Archivo de José Martínez Guerricabeitia en PARES:

http://pares.mcu.es/ParesBusquedas20/catalogo/description/172333
} 


\section{Documentos sobre la salida y el retorno del Exilio español en el AGA}

En relación al tema que nos ocupa, y debido al enorme volumen documental que custodia, en el AGA hay que destacar dos agrupaciones documentales.

Por un lado, se encuentra la documentación producida por las tres administraciones paralelas del franquismo (la Administración Central, el Movimiento Nacional y la Organización Sindical) y que aporta información sobre el exilio interior, la represión franquista, las actividades del Exilio exterior y especialmente, el retorno y acogida de los exiliados a España.

Por otro lado, el AGA custodia los documentos de algunas de las organizaciones de ayuda a los republicanos españoles en México como la JARE, CAFARE, CTARE, entre otras.

Ante la imposibilidad de citar todos los fondos de interés producidos por las administraciones paralelas del franquismo se enumeran las fuentes primordiales como son los fondos diplomáticos y consulares del Servicio Exterior de España en Francia, la documentación de la Delegación Nacional del Servicio Exterior del Movimiento o la de la Comisión Coordinadora de Repatriados. Por último, se hace referencia a la documentación de los organismos de ayuda creados por la II República en el Exilio.

\section{El Servicio Exterior de España en Francia}

La documentación del Servicio Exterior de España en Francia (Embajada y Consulados españoles acreditados en el país galo) constituye un grupo de fondos esencial para el estudio de las vicisitudes de los españoles que cruzaron la frontera, durante la contienda y sobre todo a partir de 1939, huyendo de la represión franquista y de su situación en los campos del Midi francés, así como del resto de su devenir futuro.

Los principales fondos documentales que custodia el AGA para el estudio de este tema serían: Consulado de España en Hendaya (1845-1994); Consulado de España en Lyon (1900-1953); Consulado de España en Marsella (1843-1965); Consulado de España en Niza (1912-1953); Consulado de España en Pau (1929-1949); Consulado de España en Toulouse (1928-1936); Consulado de España en Bayona (1814-1952); 
Consulado de España en Burdeos (1756-1939); Viceconsulado de España en San Juan de Luz (1845-1939) y la Embajada de España en París (1825-1986) ${ }^{37}$.

En esta rica documentación nos vamos a encontrar informes de los campos de internamiento de españoles, noticias sobre paraderos, listados de refugiados fallecidos, solicitudes de repatriaciones, legislación sobre la materia, etc. ${ }^{38}$

\section{Servicio de Repatriación de Menores}

Sobre la documentación que custodia el AGA relativa al retorno de los exiliados a España, hay que distinguir, por un lado, la documentación sobre repatriación de menores, y por otro, el retorno de los españoles en general y de los llamados "Niños de Rusia” en particular.

El organismo encargado del retorno de los menores, que habían sido evacuados durante la Guerra Civil, desde sus residencias temporales en el extranjero, fue el Servicio de Repatriación de Menores, dependiente de la Delegación Nacional del Servicio Exterior del Movimiento Nacional, organismo que dirigió la política exterior del régimen durante el primer franquismo ${ }^{39}$.

Dicho Servicio ha dejado su huella documental en la serie de expedientes de repatriación de menores, que comprende cerca de doce mil expedientes nominativos, con fechas de 1937 a 1960. Además, entre la documentación también hay fotografías de colonias de menores en España y en el extranjero ${ }^{40}$.

\section{Comisión Coordinadora de Repatriados}

\footnotetext{
${ }^{37}$ Servicio Exterior de Francia en PARES: http://pares.mcu.es/ParesBusquedas20/catalogo/contiene/2004

38 Aparte de Francia, es importante la documentación generada por el Servicio Exterior de España en Iberoamérica, principal receptora del Exilio de 1939. A destacar los fondos documentales de las representaciones diplomáticas y consulares de: Embajada y Consulado de España en La Habana (19051960); Guatemala: Embajada y Consulado del Gobierno de la II República en el Exilio (1945-1954); Delegación Diplomática de la República en el Exilio en México; Embajada de España en Santiago de Chile (1847-1948) y Embajada de España en Venezuela (1817-1962).

${ }^{39}$ Delegación Nacional del Servicio Exterior en PARES:

http://pares.mcu.es/ParesBusquedas20/catalogo/description/167577

40 IDD (09)017.022: Cajas 52/02080 - 52/02884 (85 cajas). Base de datos nominativa con 11.324 expedientes. También IDD 09)017.012 (páginas 24 - 31): Signaturas: 51/21108 - 51/21131 (24 cajas).
} 
Respecto a la repatriación de los llamados Niños de Rusia, el Ministerio de la Gobernación creó la Comisión Coordinadora de Repatriados (CCR), que se ocupó de la organización de las expediciones de retorno a España ${ }^{41}$.

Los exiliados españoles en la Unión Soviética retornaron entre 1956 y 1957, junto a los expedicionarios de la División Azul.

La documentación de la CCR comprende expedientes nominativos de repatriados ordenados alfabéticamente por expedición, con fechas extremas de 1956 y 1961, y ocupa un volumen de treinta cajas.

Una vez retornados a España, el régimen franquista utilizó los mecanismos de la Organización Sindical para que los españoles se integraran socialmente en el país, dotándoles de un puesto de trabajo a través del Servicio Nacional de Colocación de Sindicatos, con su Obra de Lucha contra el Paro ${ }^{42}$. Sin embargo, no todos los repatriados consiguieron adaptarse a su nueva situación en España, y en algunos casos, regresaron a su país de acogida.

Aparte de esta documentación, sobre repatriaciones en general el AGA custodia, dentro del fondo del Consejo Supremo de Justicia Militar, la serie de Expedientes de Repatriación de Exiliados, con fechas de 1943 y $1956^{43}$.

\section{Organizaciones de Ayuda a los Republicanos Españoles en México}

Este importante grupo de fondos ha sido transferido al AGA por el Archivo Central del Ministerio de Asuntos Exteriores y contiene la documentación producida por los sucesivos organismos de ayuda a los españoles refugiados en México:

-JARE: Junta de Auxilio a los Republicanos Españoles (1939-1942).

-CAFARE: Comisión Administradora del Fondo de Auxilios a los Republicanos Españoles (1942-1945).

\footnotetext{
${ }^{41}$ Registro de autoridad de la Comisión Coordinadora de Repatriados en PARES: http://pares.mcu.es/ParesBusquedas20/catalogo/autoridad/153140

${ }^{42}$ Delegación Nacional de Sindicatos en PARES: http://pares.mcu.es/ParesBusquedas20/catalogo/description/167515

${ }^{43}$ IDD (02)081.000: Signaturas: 61/19620 - 61/19651 (32 cajas). Base de datos nominativa con cerca de cuatro mil expedientes descritos.
} 
-CTFARE: Comité Técnico del Fideicomiso de Ayuda a los Republicanos Españoles (1945-1948) ${ }^{44}$.

La documentación ocupa cerca de medio millar de cajas y está descrita en base de datos. Más de la mitad de la misma se refiere a la Sección de Socorros, es decir, a la oficina que concedía las prestaciones económicas, sanitarias y educativas, razón de ser de todas estas entidades de ayuda a los españoles a su llegada al país de acogida.

Por tanto, la serie documental fundamental es la de Expedientes de auxilio a los españoles exiliados en México, con fechas extremas de 1940 a 1948, y que ocupa un total de 240 cajas.

Además, se generó otra documentación importante como listados de embarque de los pasajeros de los barcos fletados a América, correspondencia con autoridades mexicanas, documentación de instituciones educativas creadas en México por los refugiados españoles (Colegio Madrid, Instituto Luis Vives, etc.) ${ }^{45}$.

\section{CONCLUSION}

Los Archivos Estatales del Ministerio de Cultura han sido continente y contenido de la memoria documental del Exilio y de su retorno a España.

Contenido pues han rastreado, localizado, recuperado y descrito las fuentes externas conservadas en otros países, debido a la diáspora personal y documental.

Continente porque custodian fuentes documentales para su estudio, descritas en bases de datos y disponibles al público en Internet. Esta documentación, original o copia, se viene describiendo y digitalizando en el Portal PARES y en sus micrositios desde hace años ${ }^{46}$.

Además de los documentos y sus objetos digitales, el Portal PARES ha

\footnotetext{
${ }^{44}$ JARE en PARES: http://pares.mcu.es/ParesBusquedas20/catalogo/autoridad/122870

CAFARE en PARES: http://pares.mcu.es/ParesBusquedas20/catalogo/autoridad/152466

CTFARE en PARES: http://pares.mcu.es/ParesBusquedas20/catalogo/autoridad/152493

${ }^{45}$ Esta documentación se complementa con el ya mencionado Archivo de Carlos Esplá, que se custodia en el CDMH de Salamanca.

46 Micrositios de PARES:

http://pares.culturaydeporte.gob.es/descubre-mas-exposiciones-virtuales/portales-tematicos.html
} 
desarrollado un Fichero de Autoridades, que proporciona información de contexto sobre las personas, familias, instituciones, materias y lugares vinculados al documento.

Actualmente, están identificados en PARES cerca de setenta mil registros de autoridad, de los que una tercera parte son personas. De este porcentaje de registros onomásticos de PARES, cerca de cinco mil quinientos corresponden a exiliados españoles de la Guerra Civil, siendo la mitad de ellos mujeres, por lo que hay que poner en valor este dato que demuestra que el Exilio español de 1939 también fue femenino ${ }^{47}$.

\section{APÉNDICE DOCUMENTAL}

Imagen no 1. Regreso a España de niños repatriados por la Delegación Especial de Evacuación y Repatriación de Menores

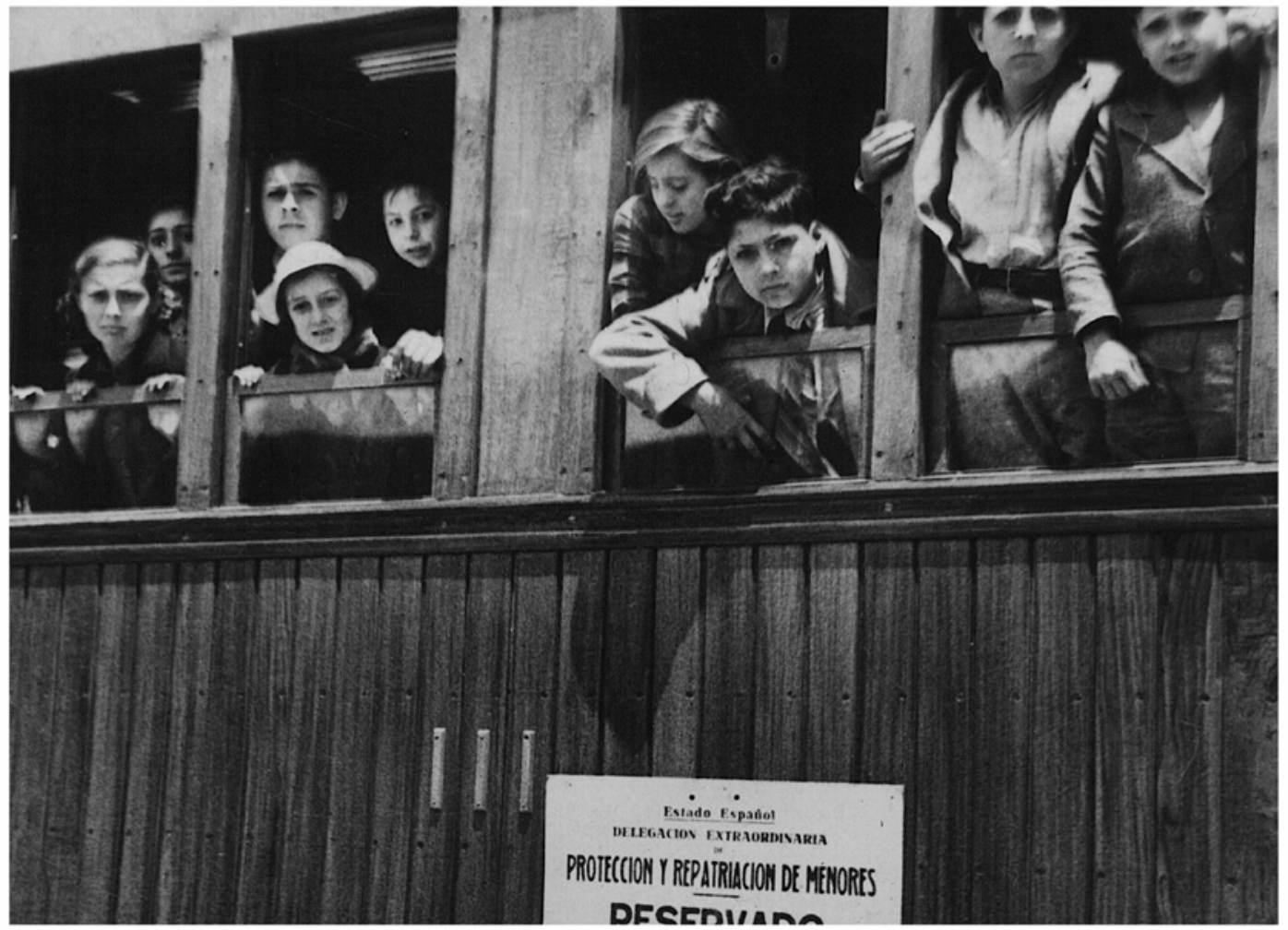

Fuente: AGA,33,00800,01

\footnotetext{
${ }^{47}$ Exiliados en PARES: http://pares.mcu.es/ParesBusquedas20/catalogo/autoridad/103530
} 
Ma Josefa Villanueva Toledo

\section{Imagen $n^{0}$ 2. Expediente de subsidio de la JARE a favor del escritor Max Aub tras} su llegada a México

AL COMITE DE SOCORROS:

El que suscribe (nombre y dos apellidos) beax aub Hewhreu unts

llegado en el vapor ferpa Pus to , al puerto de Veracruz, el dia 1 de vetulre de 1942, procedente de Caloblouca

SOLICITA: Se le conceda el subsidio establecido para los procedentes de Francia y Africa, haciendo constar que con el suscrito han llegado los siguientes familiares:

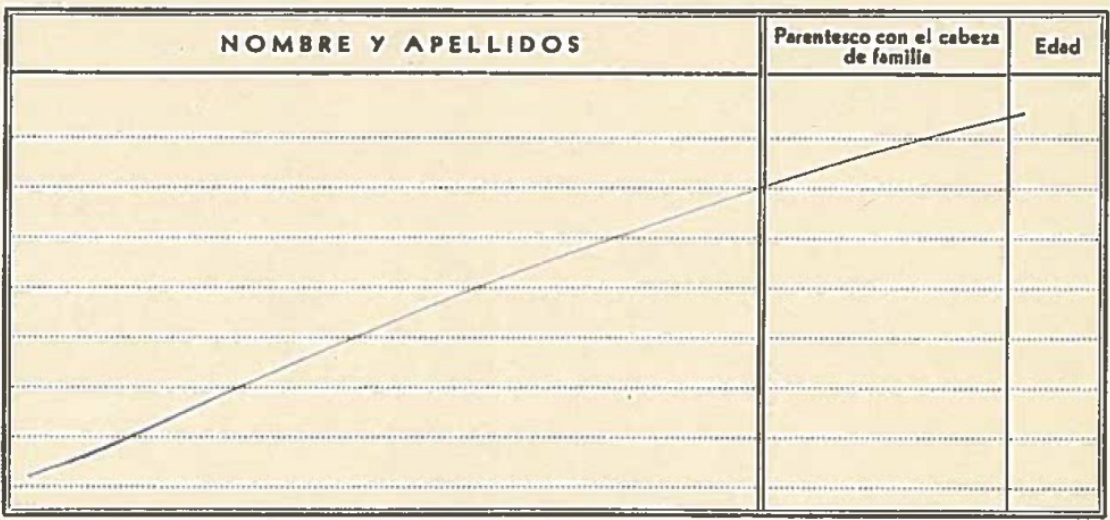

Asimismg hace constar que en Francia o Africa, percibía el subsidio mensual de 1000 francos, según acredita con los documentos que une a la presente instancia.

México, D.F. 6 de actuthe de 1942.

Domicilio actual:
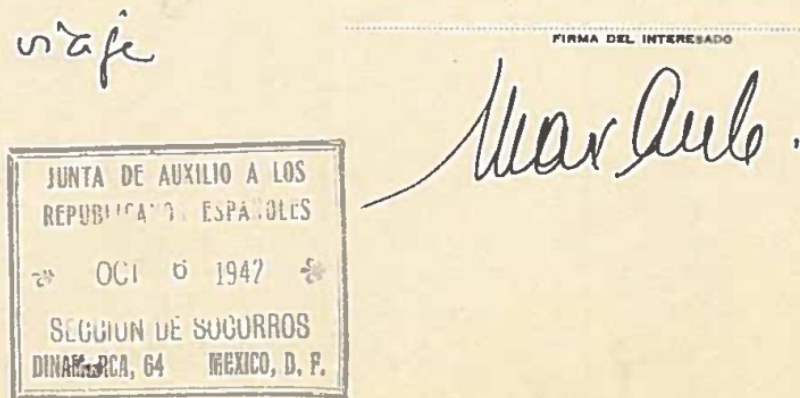

Fuente: AGA, 12,02706,06 
Imagen no 3. El vicecónsul de España en Niza informa al Cónsul en Marsella sobre la deplorable situación de los españoles refugiados en el campo de Mandelieu

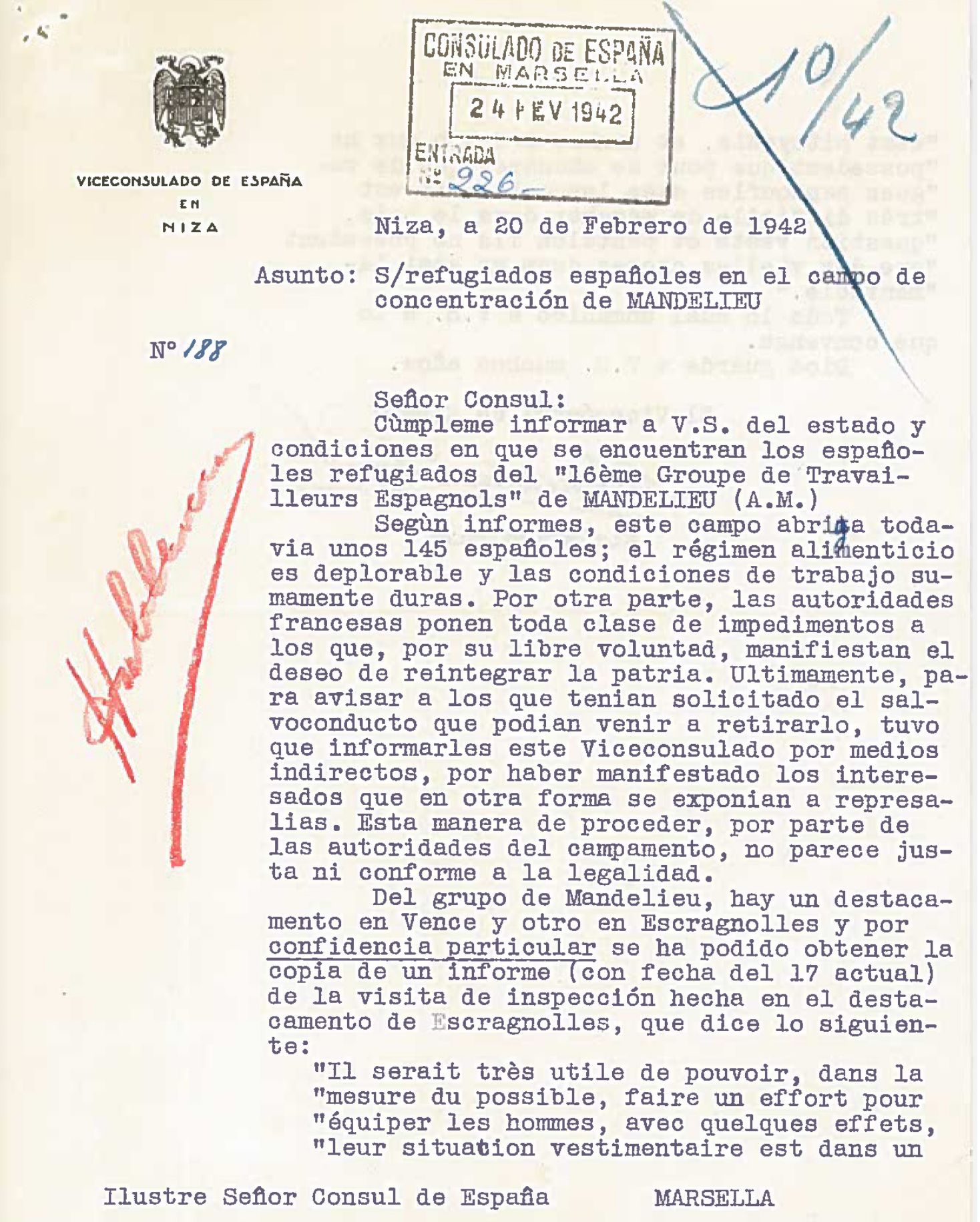

Fuente: AGA,54,04769 
Imagen $n^{0}$ 4. Informe sobre la situación de niños huérfanos españoles en el campo de Argelés-sur-Mer

$$
\text { 3.- }
$$

En total un 1mporte de 80.000 francos y sdemás la ayuda necesaría para materlal escolar, juguetes sportivos, productos de higlenfo, eto, eto.

\section{III.- AYUDA ESPECIAL AL CAMPO ARGELES}

Es neceserio aportar espeolalmente una ayuda muy importante a este campo donde hay más de 4000 nifios, viviendo en barracas de madera, siendo huérfanos muohos de ellos. Ia organización del campo permito aportar a 108 nifios una ayuda muy metódica e inoluso constructiva. Asi por ejemplo en el campo funolona una "Gota de leohe", para los nif́os de pecho, que son numerosos, celculándose en unos 300 por 10 menos..

Existe también una escuela conf una verdudera orgunlzación de maestros espan̂oles, dirigida por un Director de enselianza. Las escuelas de aprend10es, para 108 muchachos de 13 a 16 ấos, estaban on vías de creación, haola el 25 di olembro últ1mo. Y se esté esperando aotualmente una respue ta detallada dol Comandante del Campo sobre las posibllidades de ayuda por parte de la Organizaolón.

Por otra parte, se prapara un segundo viaje, a Argelés, en el curso del cual se hará una distribuolón de vest1dos, calzados, telas y se estudirán las posibilidudes de contribulr a una mejora del régimen de 108 nlîos on lo que conolerno a la ayuda oultural y especial a la "Gota de leohen. S1 se han de dar clfras necesarias para la ayuda se llegarla a un total enorme; sin embargo no se pueden contar menos de 50 francos por nlîo, 10 que representa una cantidad de 200.000 francos absolutamente indispensables, al menos durante 108 dos primeros meses a fin de obtener sensibles mejoras en la vida muterlal $\mathrm{y}$ cultural de 108 niros.

Con la simple lectura de lo que antecede se llega a la oonclusión de que aún existen on Francia una gran cant1ded de n1ños espainoles, muchos de ellos huérfanos, ouyo relntegro a la madre patrla podrla procurarse por 108 medios posibles. I posiblemente la mlama 0floina da que se da cuenta, podrla proporolonar note detallada de 108 nllios, con sus nombres, apellidos y demás olrcunstanolas, par que pudieran ser reclamados por sus familiares u parientes, sin perjuiolo de otras getiones que, posterlormente, puedan realizarse.

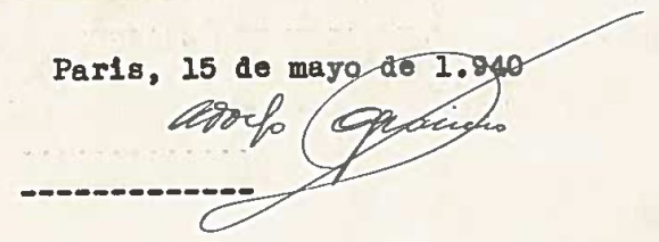

Fuente: AGA,54,11361 
Imagen $n^{0} 5$ Carta manuscrita de un niño español evacuado a Rusia a su madre en España

Rusia lenengrado Costrain aca 4 definionio de 19737 Luerida madre en el barco nos maresemos al rastar por aguats alemanas ubs un oleaje y elbarco andaba y Raberto no y es fam tomio echo dier beces da proyilla nos recibieron con musica lon $y$ al llegar a leastran nan talones largas y dale a lioneros y nos andoo

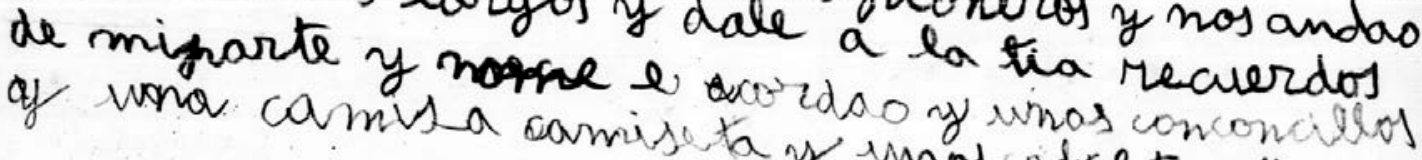

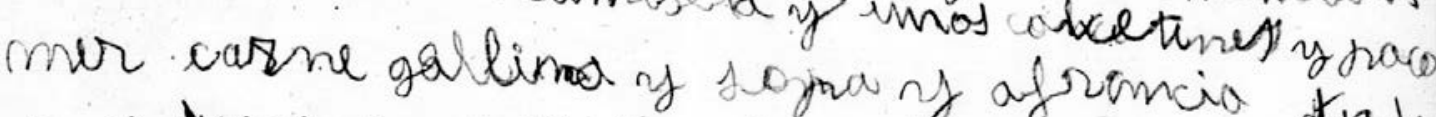
mos recosas a rusia ance dias ancia trade hocolote mucho chacolate mivelaong estamas miury tion $5 / 11$ bebar of mama y jasha are este

Fuente: CDMH, PS, BIL, C0005, EXP0011,018 


\section{Imagen no 6. Ficha de niña española evacuada durante la Guerra Civil a Francia}

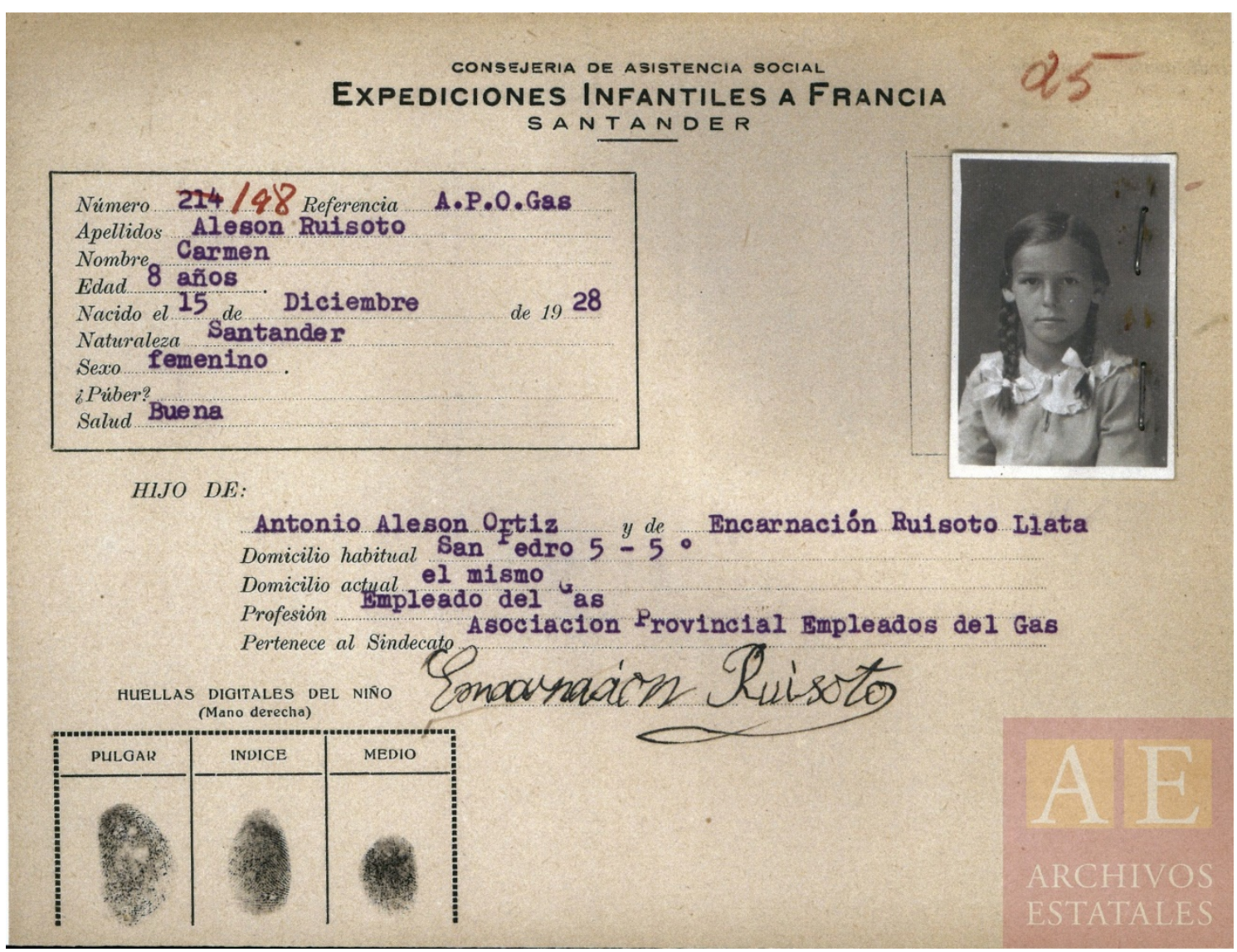

Fuente: CDMH, PS, SANTANDER,O,C0109,001 


\section{Imagen $n^{0}$ 7. Llegada de refugiados españoles a México a bordo del Sinaia}

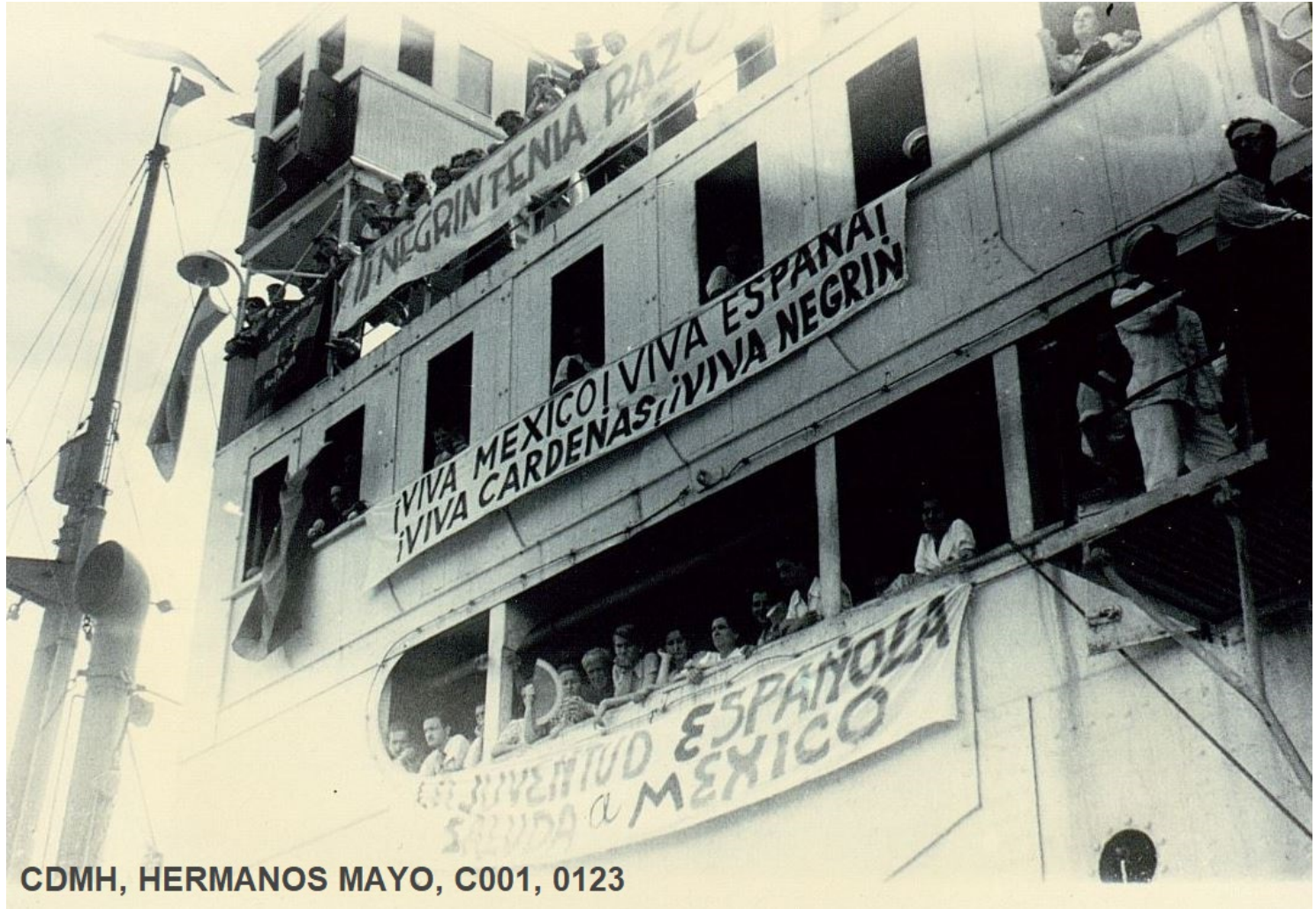

Fuente: CDMH, HERMANOS MAYO,C001,0123 
Imagen $n^{0}$ 8. Llegada a Valencia de españoles repatriados desde la Unión Soviética

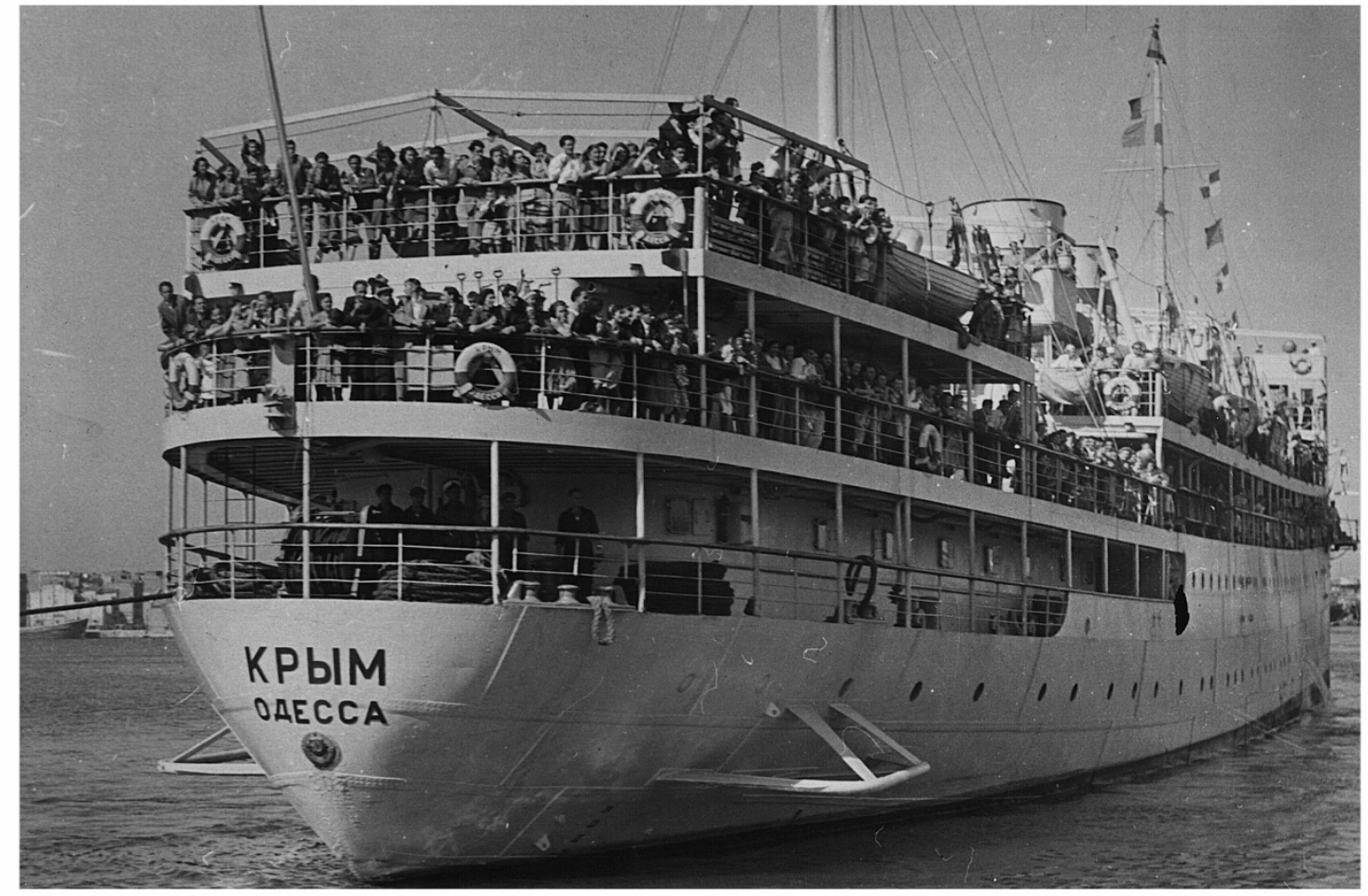

Fuente: AGA,33,01675,018,001 
Ma Josefa Villanueva Toledo

Imagen $n^{0}$ 9. Refugiados españoles en el campo de concentración de Bram (Francia)

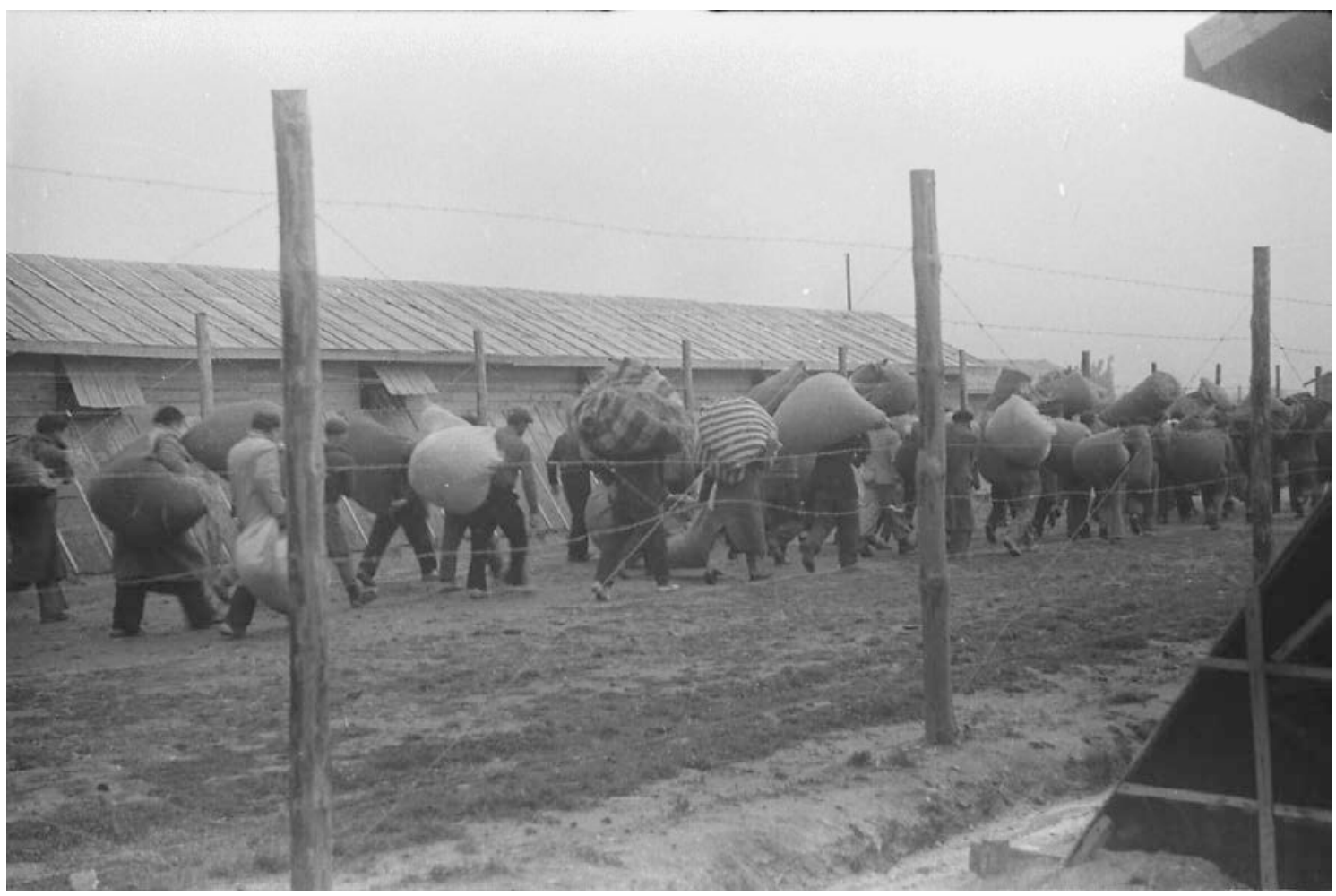

Fuente: CDMH, Centelles, 03564

Imagen $n^{0}$ 10. José Giral a bordo del vapor Flandre camino del exilio en México

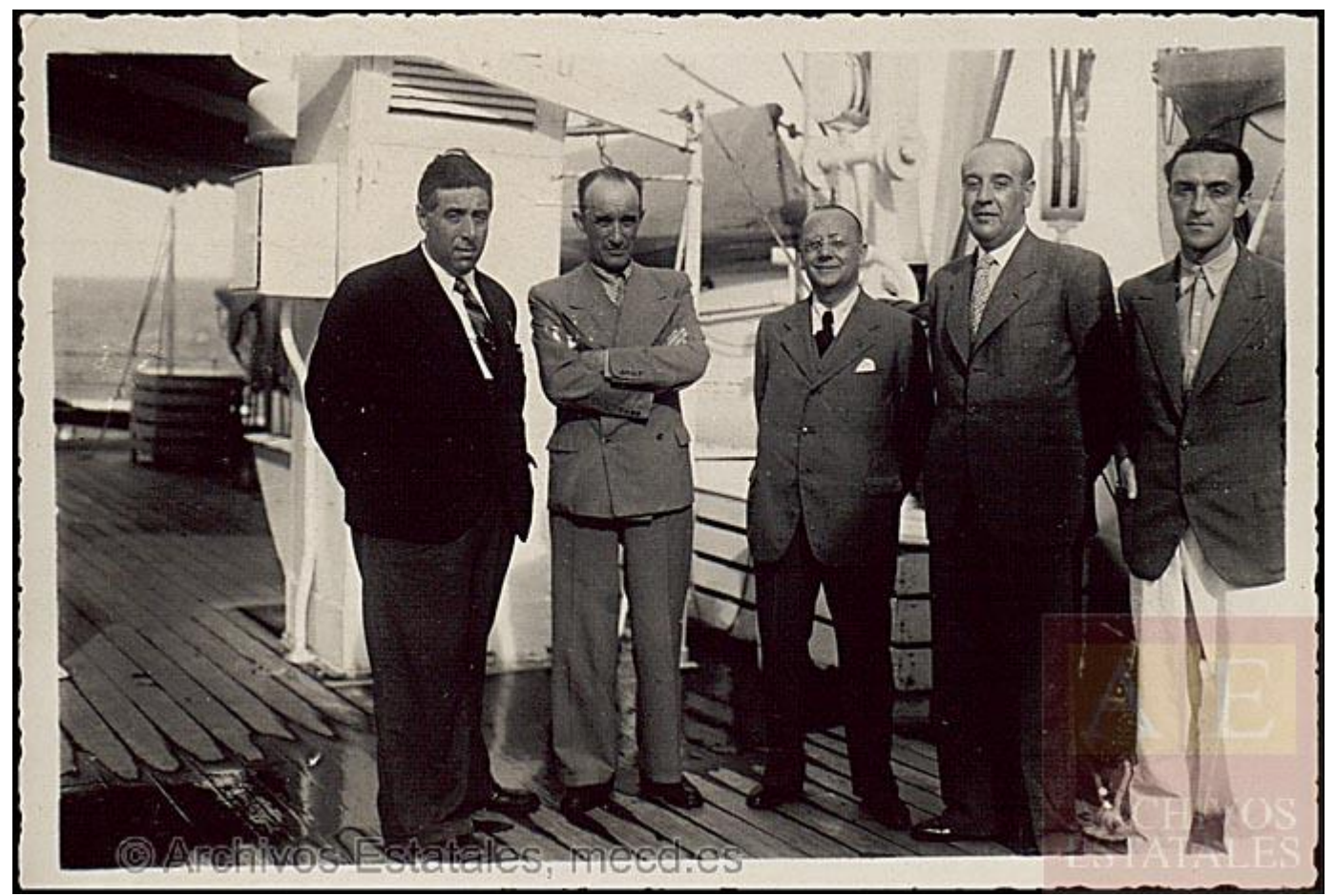

Fuente: AHN, Diversos-Jose_Giral,20, N.14 
Ma Josefa Villanueva Toledo

\section{Imagen $n^{0}$ 11. Certificado de defunción de Manuel Azaña expedido por el Consulado de Toulouse}

CONSULAD0

DE ESPAÑA EN

\section{RE GISTRO C I VIL}

Sección III.-DEFUNCION

Declaración de datos para la inscripción.

DEL, FALLECIDO: Nombre KAHUML_, apellidos (1) AZAFIA DTAZ

sexo varón edad 59 anos, naturaleza Aloalá de Henarpoofesión u oficio Abogado

domicilio

Hijo de Bsteban domiciliadoen difunto de profesión

u oficio

E hijo de Josefina , de profesión u oficio difunte

Casado con $D^{2}$ Dolores Rivas Cherif, edad 36 años, naturaleza Med̂rid

profesión u oficio sus labores

Hijos Io tuvieron desoendencia

Ocurrió el fallecimiento a causa de enfermedà a las_ horas del día 3 de Nov fembre de 1940 , en la (2) Montauban de (Exanoia), núm., piso

Dejó testamento de fecha (3) sin testamento, otorgado en la ciudad de

siendo el Notario autorizante

Recibió sepultura en Jontauban

DEL DECLARANTE: Nombre Jesús , apellidos Fernandez Conde

natural de Madreida de estado ossado , edad 60 anos, profesión u oficio Abogado

domiciliado en Ladria , en su calidad de (4) Abogado de 105 herederos

Fsta defunción se halla inserita en el Registro Civil local de t) Consulado de Esparfa en con fecha

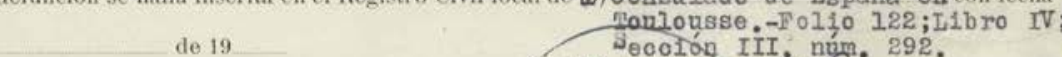
de 19 $0130122 ;$ Tibro IV;

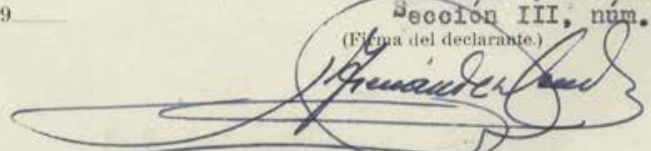

Queda inserita en el Registro Civil de este Consulado con el nilim de fecha de de 19 en el tomo folio

(Firma del Secrotariont

(1) Los hijos legitimos, de padres casados, el primero del padre y el primero de la madre, Los hijos naturales, reeonocidos por el padre o por la madre, los dos del padre o de la madre que reconozca.

(3) Si ha muerto abintestato, expresar "sin testamento". Expresar fecha, lugar y Notario autorizante del testamento.

(4) Indicar el parentesco con el fallecido o motivo per el que solicita la inscripción.

5) Si se trata de inseripción directa, déjese en blanco y acompañese eertificado del facultativo que haya comprobado la defuneión.

Fuente: AGA,82,14411,022,011 
Ma Josefa Villanueva Toledo

Imagen $n^{0} 12$. Dibujo post-mortem de Manuel Azaña realizado por el pintor exiliado Juan Alcalde

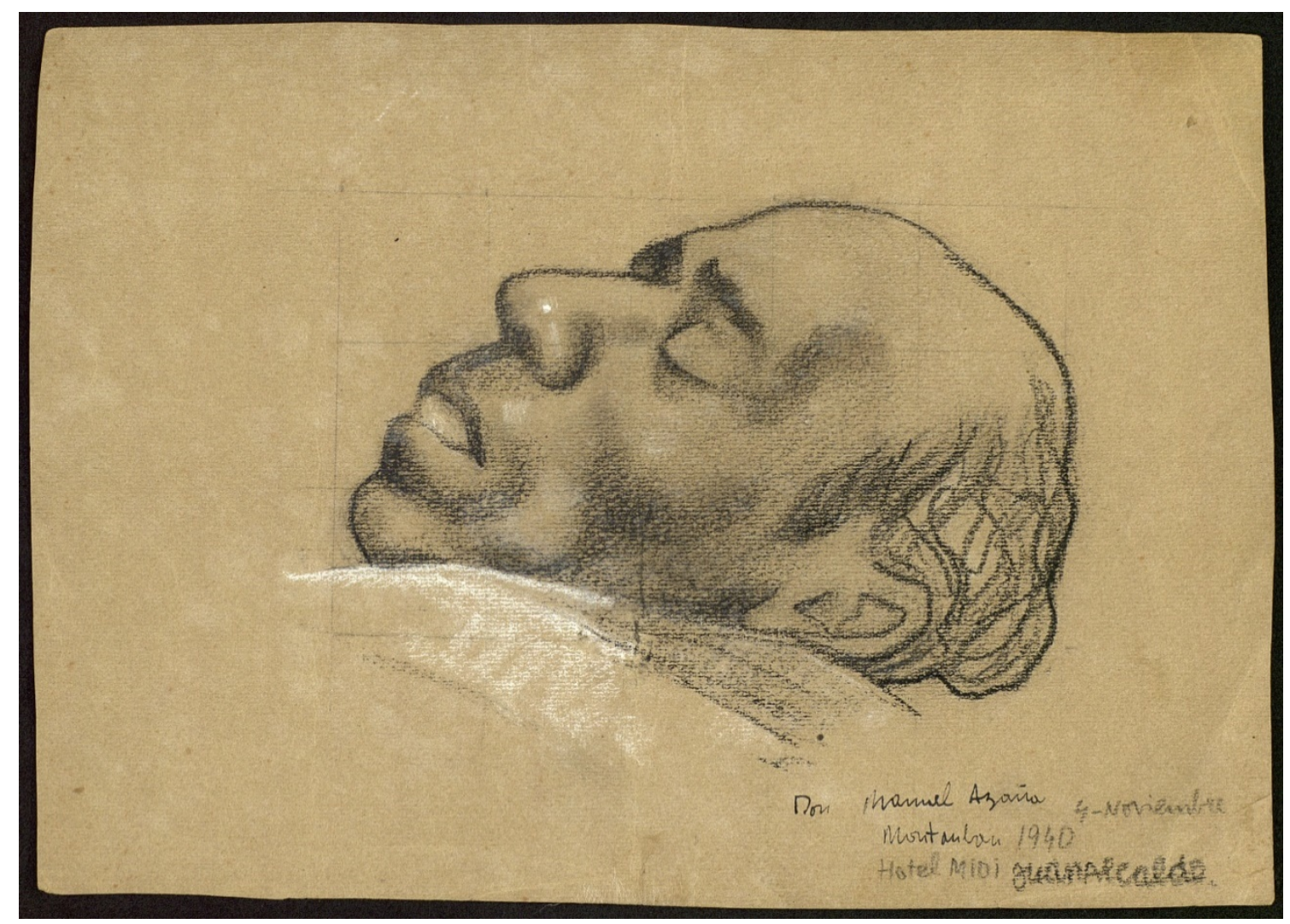

Fuente: AHN, Diversos-Colecciones, car.41,n.1,01 


\section{Imagen $n^{0}$ 13. Banquete de la Unión de Profesores Españoles en el Extranjero con} Victoria Kent como única asistente femenina

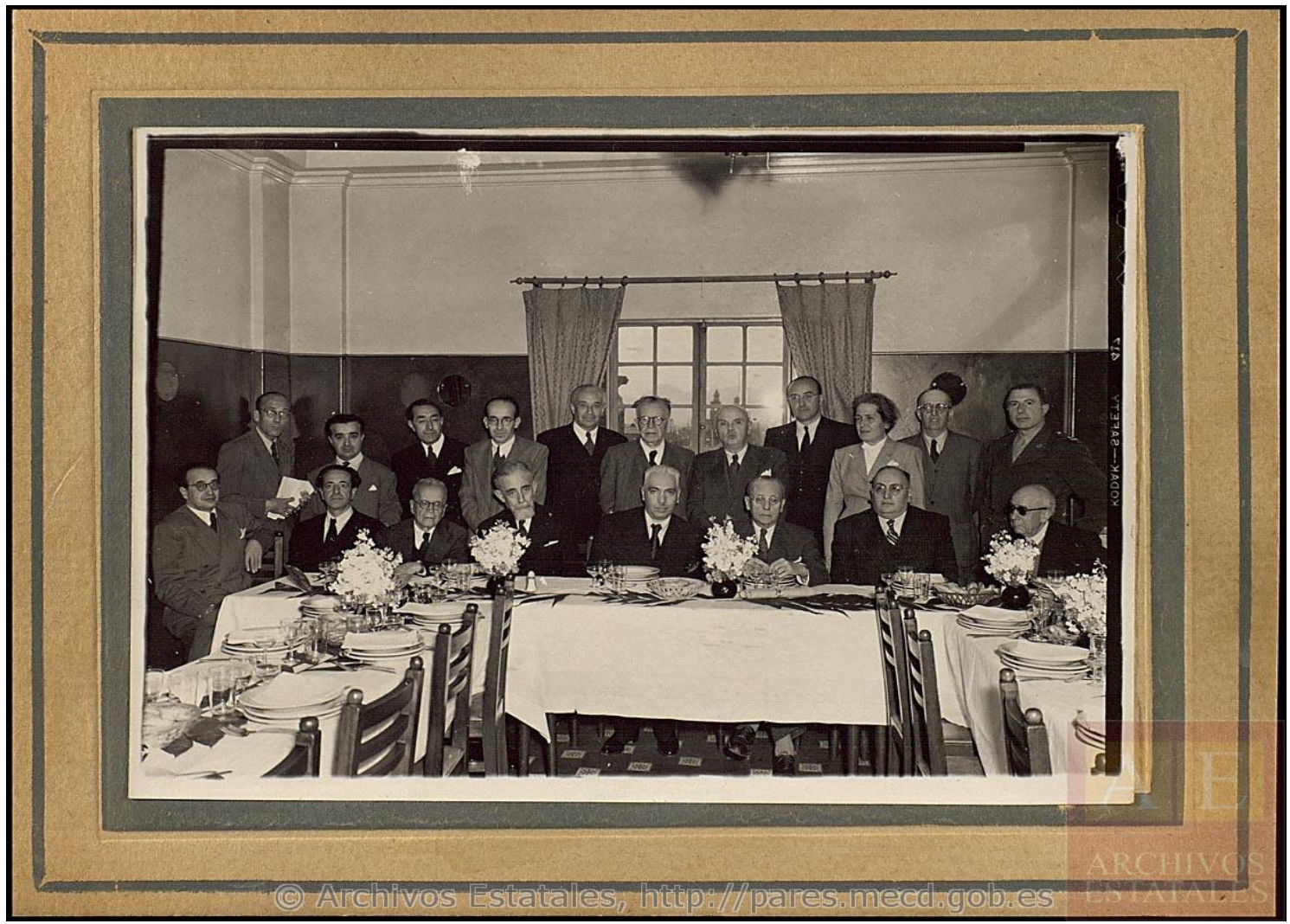

Fuente: AHN,Diversos-Jose Giral,21,N.46 
Imagen $n^{0}$ 14. Ficha de inscripción de la oftalmóloga española Trinidad Arroyo en el Registro de Inmigrantes en México como asilada política

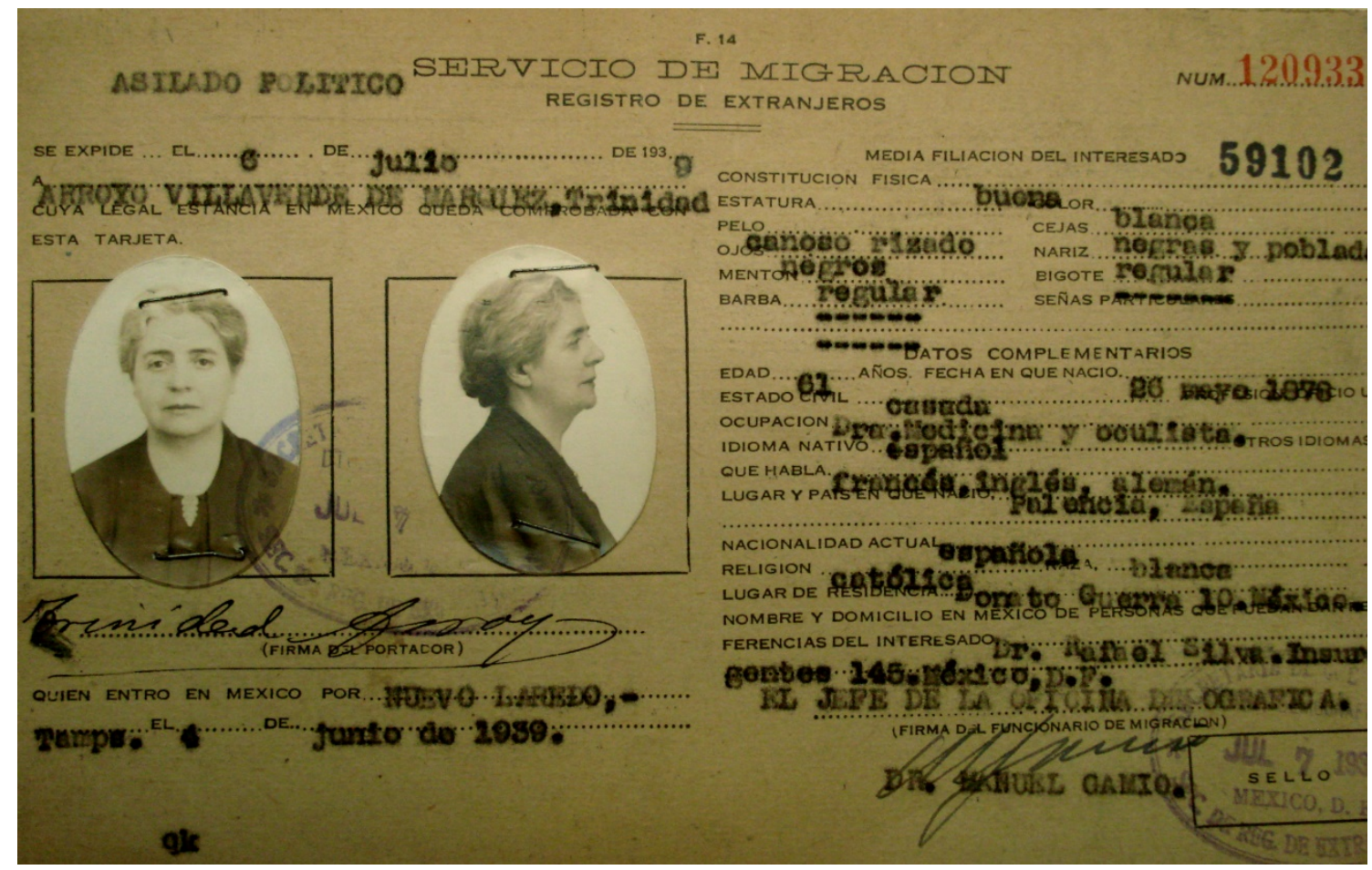

Fuente: AGA,REMEX,M0004,0567 


\section{BIBLIOGRAFÍA DEL EXILIO REPUBLICANO ESPAÑOL EN CCBAE}

Abellán, José Luis, dir. El exilio español de 1939. Madrid: Taurus, 1976-1978.

Alted, Alicia y Llusia, Manuel, dirs. La cultura del exilio republicano español de 1939: actas del Congreso Internacional celebrado en el marco del Congreso Plural: "Sesenta años después", (Madrid-Alcalá-Toledo, diciembre de 1999). Madrid: Universidad Nacional de Educación a Distancia, 2003

Aznar Soler, Manuel y Ramón López García, José Ramón, eds. Diccionario biobiográfico de los escritores, editoriales y revistas del exilio republicano de 1939. Sevilla: Renacimiento, 2016.

Archivo General de la Nación de México. Inventario de las copias fotográficas de los Hermanos Mayo depositadas en la Sección Guerra Civil del Archivo Histórico Nacional en Salamanca. [S.1.: s.n., s.a.]

Bonet, Juan Manuel, comisario. 1939. Exilio republicano español. Madrid: Ministerio de Justicia: Ministerio de Educación y Formación Profesional, 2019.

Cuesta, Josefina y Bermejo, Benito, coords. Emigración y exilio: españoles en Francia, 1936-1946. [Madrid]: Eudema, D.L. 1996.

Dávila, Alfonso; Lijarcio, Juan José y Sierra, Carmen. "El exilio en los archivos de titularidad del Ministerio de Cultura". Migraciones y exilios, 8 (2007): 11-32

Díaz, Cristina. "El Portal de Movimientos Migratorios Iberoamericanos". Anuario americanista europeo, 11 (2013): 1-8

Domínguez Prats, Pilar. De ciudadanas a exiliadas: un estudio sobre las republicanas españolas en México. Madrid: Fundación F. Largo Caballero: Cinca, 2009

Encinas Moral, Ángel Luis. Fuentes históricas para el estudio de la emigración española a la U.R.S.S. (1936-2007). Madrid: Exterior XXI, 2008

Hernández Luis, José Luis. "Fuentes para el estudio del exilio cultural en el Centro Documental de la Memoria Histórica". Laberintos: revista de estudios sobre los exilios culturales españoles, 16 (2014): 79-90

Índices de los documentos de la ayuda a los republicanos españoles en el exilio y del gobierno de la República en México. [Madrid]: Ministerio de Asuntos Exteriores, Secretaría General Técnica, Dirección de Documentación y Publicaciones, [ca. 1984].

Instituto Nacional de Antropología e Historia. Proyecto de Historia Oral "Refugiados Españoles en México": Archivo de la Palabra. México: INAH, 1978-1990

La contemporaneidad española: archivos y memoria vivos: Alcalá de Henares, 14, 15, 16 y 17 de enero de 1992. Madrid: UNED, Departamento de Historia Contemporánea, 1992.

Memoria del exilio republicano español en Francia: guía de las entrevistas y archivos de la serie documental. Primera parte. Madrid: UNED, Departamento de Historia Contemporánea y Centros Audiovisuales, 1995 
Ordoñez Alonso, Ma Magdalena. Guía de documentos del Archivo del Comité Técnico de Ayuda a los Republicanos Españoles. México: Universidad Nacional Autónoma de México, Facultad de Filosofía y Letras, Colegio de Historia, 1993

Pla Brugat, Dolores. "Refugiados españoles en México: recuento y caracterización". En Los refugiados españoles y la cultura mexicana: actas de las segundas jornadas, celebradas en El colegio de México en noviembre de 1996, James Valender... et al., 381-395. México, D. F.: El Colegio de México, 1999. https://doi.org/10.2307/j.ctv3dnq03.24

Pla Brugat, Dolores, coord. Catálogo del fondo de historia oral: refugiados españoles en México: Archivo de la Palabra. México D.F.: Instituto Nacional de Antropología e Historia, 2011

Sierra, Carmen. "Noticia sobre la Guía de Fuentes para la historia de la guerra civil española, exilio, y movimiento obrero: una base de datos para acceder a información puntual de fuentes documentales". Olivar: revista de literatura y cultura españolas, 8 (2006): 209-214. 